\title{
TRACHEAL RESECTION ASSOCIATED WITH SLIDE TRACHEOPLASTY FOR LONG-SEGMENT CONGENITAL TRACHEAL STENOSIS INVOLVING THE CARINA
}

\author{
Eréa Noel Garabédian, MD, ${ }^{\mathrm{a}}$ Emmanuel Le Bret, MD, ${ }^{\mathrm{b}}$ Alain Corré, MD, ${ }^{\mathrm{a}}$ Gilles Roger, MD, ${ }^{\mathrm{a}}$ Emmanuelle Pineau, MD, \\ Patrick Bourel, MD, ${ }^{\mathrm{b}}$ Thierry Folliguet, MD,${ }^{\mathrm{b}}$ Pascal Vouhé, MD, ${ }^{\mathrm{b}}$ and François Laborde, MD, ${ }^{\mathrm{b}}$ Paris, France
}

Surgical alternatives for infants with congenital tracheal stenosis resulting from complete tracheal rings include resection with end-to-end anastomosis, ${ }^{1}$ pericardial ${ }^{2}$ or cartilage tracheoplasty, ${ }^{3}$ slide tracheoplasty, ${ }^{4}$ and more recently, free tracheal autograft. ${ }^{2}$ We report here a case of concomitant tracheal resection and slide tracheoplasty.

Clinical summary. A 4-month-old infant who had a ventricular septal defect closed at the age of 2 months was referred to our institution for critical tracheal stenosis. The child was intubated but satisfactory ventilation was impossible, despite a high peak airway pressure of $60 \mathrm{~cm} \mathrm{H}_{2} \mathrm{O}$. Examination with a rigid bronchoscope (Karl Storz Endoscopy, Inc, Tuttlingen, Germany) showed complete tracheal rings with a very severe stenosis (Fig 1). The length from the stenosis to the carina could not be precisely determined because the finest bronchoscope could not be passed through the stricture. Computed tomographic scanning and bronchography (Fig 1) showed hypoplasia of the lower two fifths of the trachea extending down to the carina and to the main bronchi with a critical stenosis located at the upper limit of the hypoplastic area.

Surgical technique. A transverse cervical incision combined with a median sternotomy was performed. Pericardial adhesions were removed and the dissection of the trachea was started between the vena cava and the aorta. It was then extended to the cervical area. The left brachiocephalic vein was divided, and the innominate artery was widely mobilized and retracted. The strap muscles were divided in the midline, and the thyroid isthmus was dissected and divided. The dissection was carried out along the anterior wall of the trachea extending to the hyoid bone, which was detached from the insertion of the suprahyoid muscles to provide better mobilization. The proximal end of the trachea was circumferentially dissected, but the distal segment was only partially mobilized to prevent devascularization. The patient was then heparinized and normothermic cardiopulmonary bypass was

From the Département d'ORL pédiatrique, Hôpital d'enfants Armand Trousseau, Université, Paris, and Département cardiovasculaire, L'Institut Mutualiste Montsouris, Paris, France.

Received for publication June 6, 2000; accepted for publication June $22,2000$.

Address for reprints: Emmanuel Le Bret, MD, Département cardiovasculaire, Institut Mutualiste Montsouris, 42 Blvd Jourdan, 75674

Paris Cedex 14, France (E-mail: emmanuel.lebret@imm.fr).

J Thorac Cardiovasc Surg 2001;121:393-5

Copyright (C) 2001 by The American Association for Thoracic Surgery

0022-5223/2001 $\$ 35.00+0 \quad \mathbf{1 2 / 5 4 / 1 0 9 7 0 2}$

doi:10.1067/mtc.2001.109702 established between the right atrium and the aorta. The trachea was first transversely transected at the level of the major stenosis (Fig 2, A). Three complete rings were resected. The distal end of the trachea was longitudinally divided along its anterior wall down to the carina. The proximal end of the trachea was also longitudinally divided but along its posterior wall, extending for the same distance (Fig 2, B). The rightangled corners of the tracheal wall represented by the meeting points of the vertical and horizontal incisions were trimmed to make a gently sloping corner. The anastomosis was performed with interrupted sutures of 5-0 polypropylene. Suturing was begun proximally and the final sutures were placed at the distal end of the tongue of the anterior wall of the trachea, which was sutured down to a point at the anterior part of the carina. Anastomotic sutures were tied externally to the tracheal lumen starting proximally and posteriorly and working down sequentially on both sides (Fig 2, $C$ and $D$ ). The endotracheal tube was replaced and ventilation was re-established. Anastomotic integrity was tested with saline solution and the patient was weaned from cardiopulmonary bypass.

The patient was extubated on the third postoperative day under bronchoscopic control and made an uneventful recovery. At 1 month, the child was doing well. The bronchoscopic examination and the follow-up computed tomographic scan (Fig 3) showed a nice tracheal repair with a wide carina without granulomatous tissue. At 5 months the patient is still doing perfectly well.

Discussion. Tracheal reconstruction with pericardial or cartilaginous patch grafting requires long-term intubation for stenting, and postoperative care is often complicated by the formation of extensive granulation tissue over the composite graft. End-to-end anastomosis cannot be performed in the case of very long segment resection or if the stenosis involves the carina. The advantages of slide tracheoplasty for long congenital tracheal stenosis in small infants are now widely known: avoidance of graft materials, avoidance of tension on the sutures, satisfactory enlargement of the trachea, and finally avoidance of impairment of the anatomic and functional growth of the trachea. ${ }^{5}$

This case report shows that slide tracheoplasty can be performed in addition to resection of a critical stenosis of more than one fifth of the trachea. The proximal two fifths of the trachea can slide over the distal two fifths and over the carina without tension. This can be achieved by an extensive mobilization of the proximal part up to the larynx and by the section of the suprahyoid muscles. In addition, slide tracheoplasty was very useful in this case to enlarge the carina. Two technical points have to be mentioned: First, the anterior part of the carina had to be opened wide with small lateral resection up to the origin of the bronchi. 

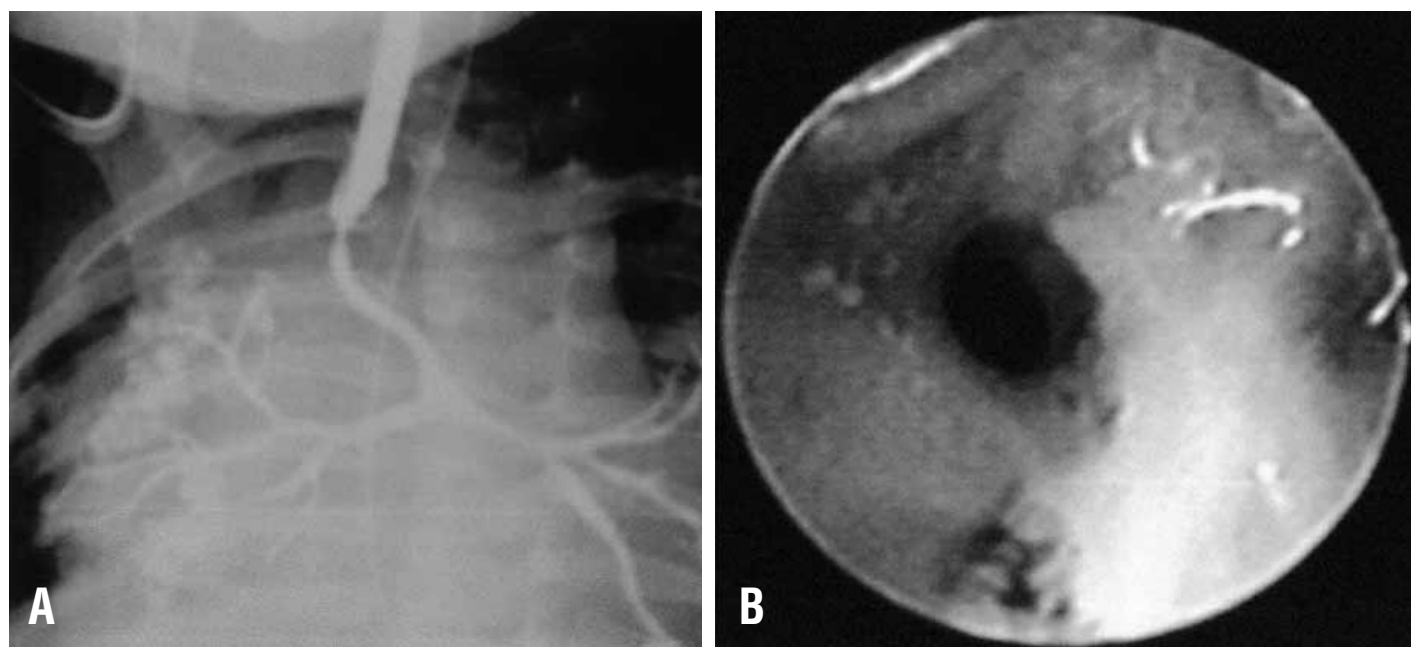

Fig 1. A, Preoperative bronchogram. B, Preoperative endoscopy.
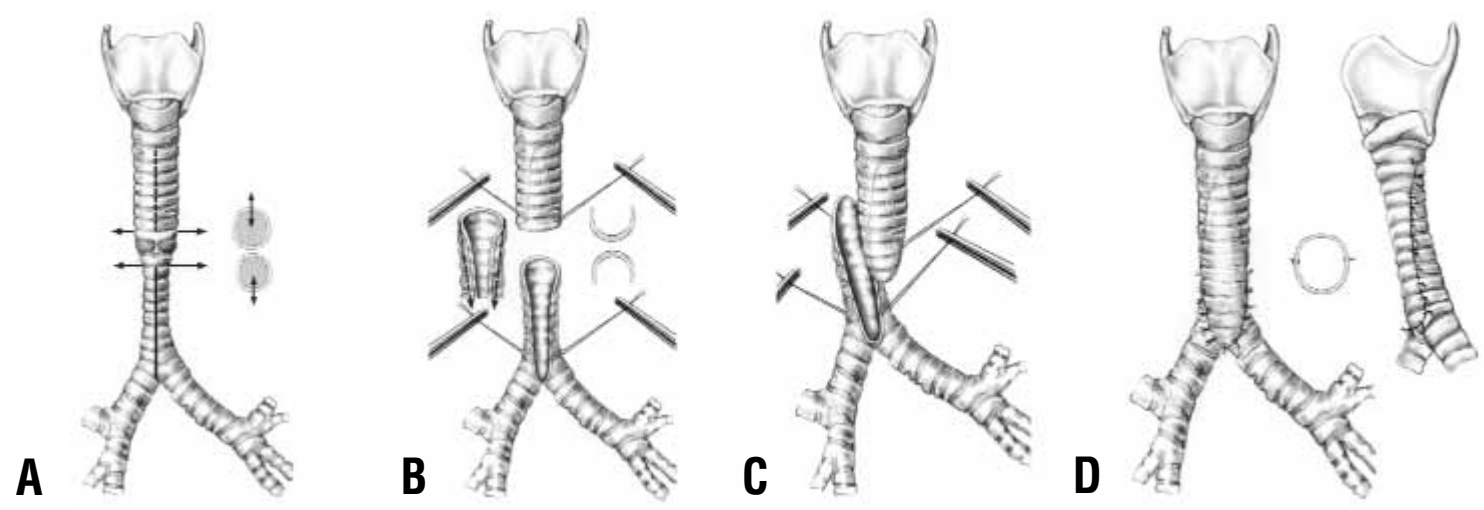

Fig 2. Localization of the tracheal lesions and technique of tracheal resection associated with slide tracheoplasty.

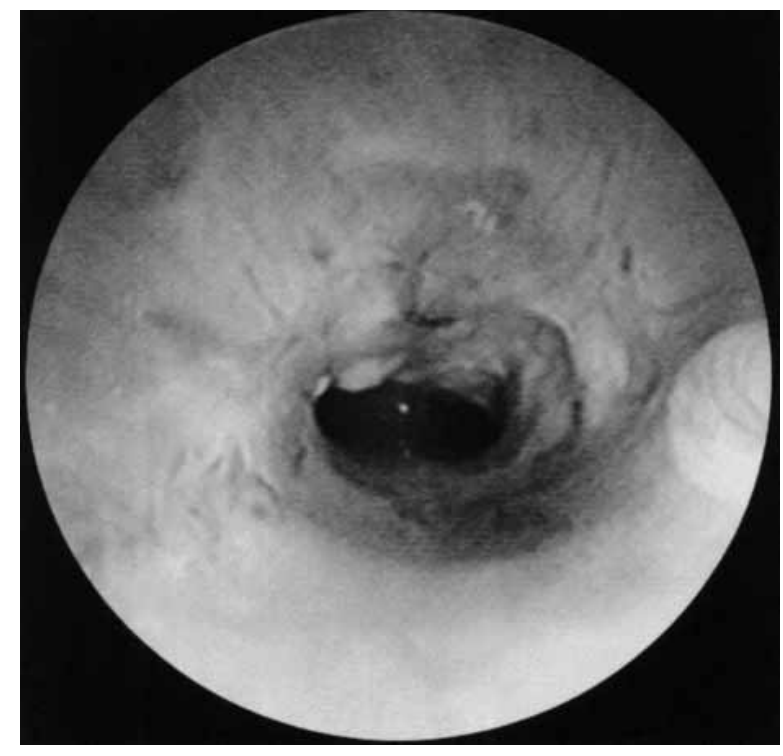

Fig 3. Postoperative endoscopy.
Second, the right-angled corners of the upper part of the trachea had to be precisely trimmed to allow adequate enlargement of the carina.

The use of cardiopulmonary bypass oxygenation allows removal of the endotracheal tube, which simplifies the tracheal repair. Postoperative care must be focused on the quality of a gentle lung ventilation with avoidance of traumatic suction to prevent granulation tissue formation. Extubation must be undertaken with endoscopic control. A multidisciplinary approach to this difficult therapy with ear-nose-throat surgeons, cardiothoracic surgeons, intensivists, and pneumologists may be one of the major keys for success.

\section{REFERENCES}

1. Mattingly WT, Belin RP, Todd EP. Surgical repair of congenital tracheal stenosis in an infant. J Thorac Cardiovasc Surg 1981;81:738-40.

2. Tsugawa C, Kimura K, Nishijima E, Matsumoto Y, Murata H. Congenital stenosis involving a long segment of the trachea: further experience in reconstructive surgery. J Pediatr Surg 1988;23:471-5 
3. Backer CL, Mavroudis C, Dunham ME, Holinger LD. Pulmonary artery sling: results with median sternotomy, cardiopulmonary bypass, and reimplantation. Ann Thorac Surg 1999;67:1738-45.

4. Tsang V, Murday A, Gillbe C, Goldstraw P. Slide tracheoplasty for congenital funnel-shaped tracheal stenosis. Ann Thorac Surg 1989;48:632-5.

5. Macchiarini P, Dulmet E, de Montpreville V, Mazmanian GM, Chapelier A, Dartevelle P. Tracheal growth after slide tracheoplasty. J Thorac Cardiovasc Surg 1997;113:558-66. 